\title{
Numerical and Experimental Study on Vibration and Noise of Embedded Rail System
}

\author{
Fangyao Yeh1, Xiaoting Chang², Yuchi Sung1,2 \\ ${ }^{1}$ Bridge Engineering Division, National Center for Research on Earthquake Engineering, Taiwan \\ ${ }^{2}$ Department of Civil Engineering, National Taipei University of Technology, Taiwan \\ Email: fyyeh@narlabs.org.tw
}

How to cite this paper: Yeh, F.Y., Chang, X.T. and Sung, Y.C. (2017) Numerical and Experimental Study on Vibration and Noise of Embedded Rail System. Journal of Applied Mathematics and Physics, 5, 1629-1637.

https://doi.org/10.4236/jamp.2017.59135

Received: May 18, 2017

Accepted: September 12, 2017

Published: September 15, 2017

\begin{abstract}
The Kaohsiung light rail transit (LRT) system first introduced embedded rail system in Taiwan. However, domestic engineering consultants are still lacking in experience of analysis, design and construction of embedded rail systems. Noise and vibration of the mass rapid transit system is an important environmental issue in an urban environment. In order to understand the environmental impact of noise due to structural vibrations caused by a train running on the rail system, this paper establishes a numerical analysis procedure to perform a simulation. There are two fundamental parts to the numerical simulation: 1) vibration response due to a moving load and 2) radiation propagation of noise induced by structural vibration. The Kaohsiung LRT is used as a case study. The real embedded rail track system is modeled using ANSYS software with finite element analysis and the dynamic time history of the vibration response of the rail caused by a moving load is obtained. Secondly, the dynamic vibration response of the rail outputted by ANSYS is then imported into the software LMS Virtual.Lab to obtain the external radiation and sound field pressure distribution transferred from the rail to a specific monitoring point, based on the boundary element method. This paper also conducts field measurements of vibration velocity and sound pressure as a train passes. Both the experimental and analytical results for noise at specific points are compared and discussed. The proposed procedure promises to be suitable for practical vibration and noise analyses for rail systems.
\end{abstract}

\section{Keywords}

Embedded Rail System, Noise and Vibration Analysis, Finite Element Method, Boundary Element Method

\section{Introduction}

Around the world, because maintenance work on various ballast track systems 
has increased year by year, the maintenance cost, including labor and equipment costs, has also increased. Meanwhile, the ballast tracks required for the sleeper, ballasts and other materials are becomingly increasingly scarce. Therefore, research and development on railway systems around the world have trended towards non-ballast track system [1] [2] [3]. This study explores the embedded rail system of the light rail transit system (LRT), which is a non-ballast track system. While normal traffic cannot mingle with a general rail system, the embedded rail system merges a general lane with road traffic, so people are free to enter. LRT runs along its route without a fence or barrier. As a results, train-induced vibration and noise directly affect people and nearby buildings. However, there have been few studies on the vibration and noise of an embedded rail system in domestic.

In this paper, the three-dimensional finite element analysis is used to study the vibration and noise characteristics of embedded rail systems. Taking the Kaohsiung LRT as an example, vibration, and noise analyses of embedded rail systems are performed. The purpose of the study is to establish a set of effective simulation procedures and methodologies, and effectively apply them to practical engineering problems.

\section{Numerical Simulation on Vibration and Noise of a Rail System}

There are two stages in the vibration and noise analyses of rail systems. The first stage uses ANSYS to determine the dynamic response by moving a load on the rail system via the finite element method [4]. The second stage uses LMS Virtual.Lab to solve the equation for the sound pressure distribution of the external radiation field via the boundary element method [5]. To verify this simulation procedure, the feasibility of the acoustic vibration analysis technique is evaluated for the embedded rail of the Kaohsiung LRT system as an example, and the numerical simulation and measurement results are analyzed and discussed.

\subsection{ANSYS Vibration Analysis Model}

The embedded rail system consists of three elements: the steel rail, the encapsulation, and the concrete slab. The Kaohsiung LRT main line use a 54R2 (41GPU) track for the steel rail section, the encapsulation uses recycled waste tires, and the concrete track bed is a no-fasteners continuous support type [6] [7]. The overall cross-section is as shown in Figure 1.

The finite element model of the embedded rail system is established with ANSYS. The soil depth is 4 meters, the width is 10 meters, and the overall length of the track is 40 meters, as shown in Figure 2. The properties of the materials of the rail, encapsulation, and concrete are shown in Table 1, and the material parameters are inputted to ANSYS for dynamic moving load analysis.

The vehicle model is simplified as a double-row concentrated moving load. All concentrated loads are assumed to be $65 \mathrm{kN}$ for train load analysis according 


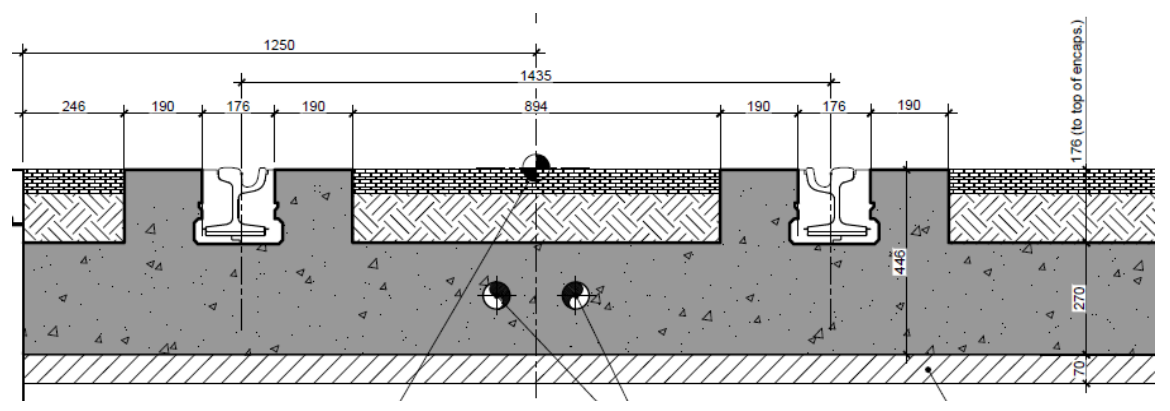

Figure 1. Cross-section of the Kaohsiung LRT (unit: $\mathrm{mm}$ ).

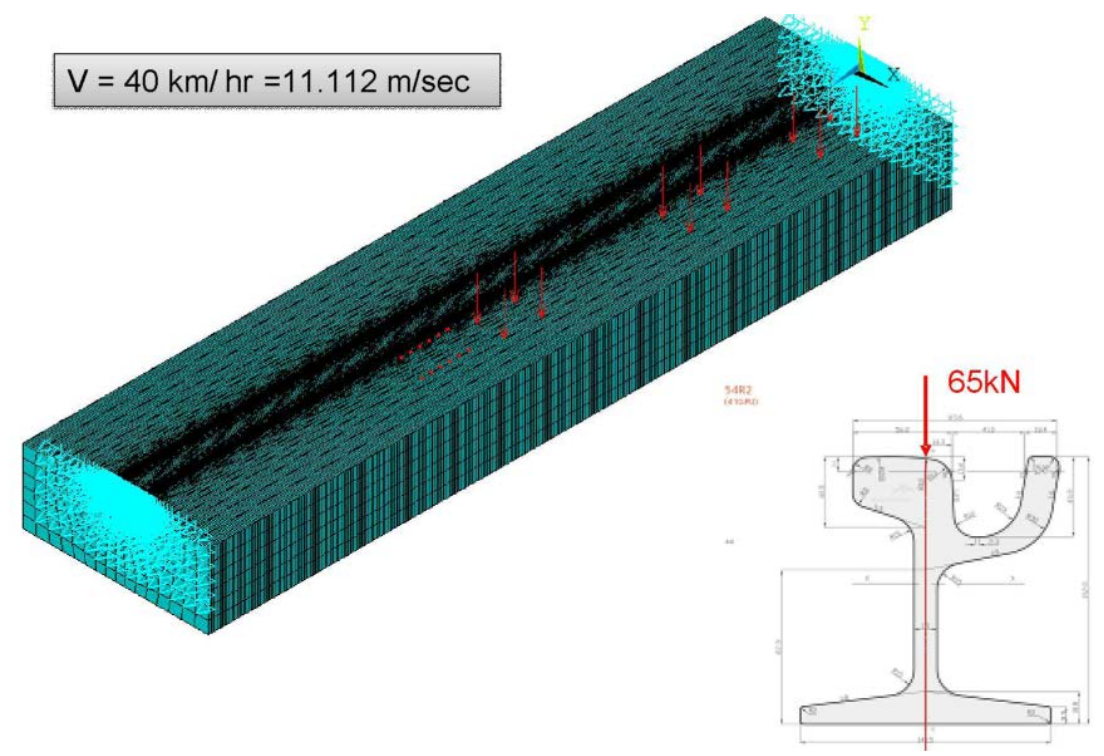

Figure 2. Finite element model of the Kaohsiung LRT.

Table 1. Material properties of the Kaohsiung LRT.

\begin{tabular}{cccc}
\hline Material & Elastic modulus (MPa) & Density $\left(\mathrm{kg} / \mathrm{m}^{3}\right)$ & Damping ratio (\%) \\
\hline Steel rail & 200,000 & 7850 & 2 \\
Concrete slab & 30,000 & 2400 & 3 \\
Encapsulation & 2.6 & 1200 & 5 \\
AC concrete & 3 & 2360 & 3 \\
Pavement concrete & 17,405 & 2400 & 3 \\
Fertile soil & 15 & 1600 & 5 \\
Soil & 40 & 1800 & 5 \\
\hline
\end{tabular}

to the original design. The boundary conditions are assumed to be at the soil boundary. Both the left and right sides of the model (X direction) and the bottom of the model ( $Y$ direction) are fixed. The deformation on both sides of the driving direction ( $\mathrm{Z}$ direction) is assumed to be zero, which is considered to be the plane strain condition. The numerical model is modeled by solid elements in order to reduce analysis time, using the modal superposition method to solve the 
equations of motion.

\subsection{LMS Virtual.Lab Sound Field Analysis Model}

The sound field analysis uses LMS Virtual. Lab's built-in transient boundary element with an air density of $1.255 \mathrm{~kg} / \mathrm{m}^{3}$ and a sound velocity of $340 \mathrm{~m} / \mathrm{s}$. The node instantaneous displacement vibration response obtained from the ANSYS analysis is taken as the boundary condition of the sound field. All node displacements are applied to the nodes mapped by the sound field and the acoustic radiation is calculated. In order to understand the sound field response of a train passing through, the sound field is calculated at a point $1.2 \mathrm{~m}$ from the top of the rail, as shown in Figure 3.

\section{Vibration and Noise Experiment of an LRT}

In this study, two different types of embedded rail systems were selected. The general embedded track measurement points were located at the intersection of Kaisyuan 4th Road and Zhongshan 3rd Road. The upper part of the measurement location was the viaduct. The grass-embedded track measurement points were located near the intersection of Kaisyuan 4th Road and Ruinan Street. The two measuring points were close to the Kaohsiung mass rapid transit (MRT) system's Kaisyuan station, which is the MRT red line R6 station.

The vibration measurement was carried out using the SPC-51 portable vibration monitoring system and the VSE-15D servo velocity-meter produced by Tokyo Sokushin Co., Ltd. The vibration was measured with measurement duration of 180 seconds for each recording and a sampling rate of $200 \mathrm{~Hz}$. The gen eral embedded track measurement points were set at $1.28 \mathrm{~m}, 4.28 \mathrm{~m}, 6.98 \mathrm{~m}$, $10.33 \mathrm{~m}$, and $13.33 \mathrm{~m}$ from the rail center. Three single-axis servo velocity-meters (VSE-15D) were set at the same location to measure the $\mathrm{X}, \mathrm{Y}, \mathrm{Z}$ directions of the vibration speed. The $\mathrm{X}, \mathrm{Y}$, and $\mathrm{Z}$ directions are expressed as the perpendicular, parallel, and vertical driving directions to the ground, respectively. The measurement setup for the general embedded track is shown in Figure 4. The grass-embedded track measurement points were set at $1 \mathrm{~m}, 3 \mathrm{~m}, 6 \mathrm{~m}, 9 \mathrm{~m}$, and $12 \mathrm{~m}$ from the rail center. The measurement setup for the grass-embedded track is shown in Figure 5.

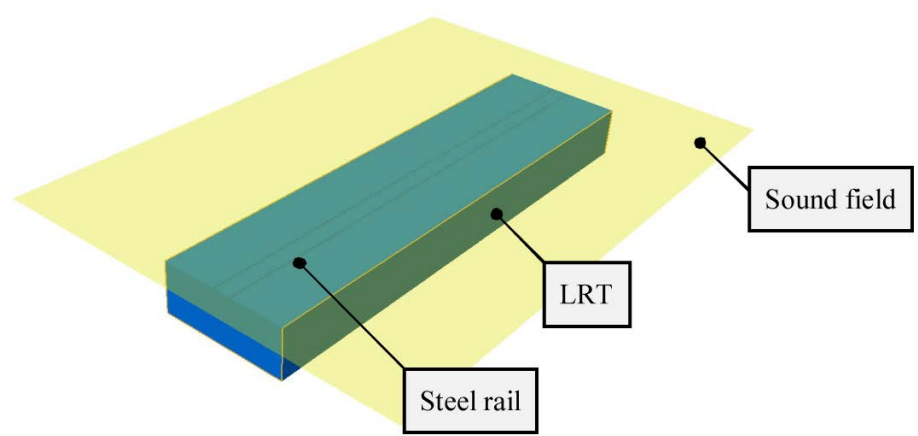

Figure 3. LMS Virtual.Lab sound filed analysis model. 


\begin{tabular}{|c|c|c|}
\hline \multirow{2}{*}{$*$} & Point & Distance \\
\cline { 2 - 3 } & 1 & $1.28 \mathrm{~m}$ \\
\cline { 2 - 3 } & 2 & $4.28 \mathrm{~m}$ \\
\cline { 2 - 3 } & 3 & $6.98 \mathrm{~m}$ \\
\cline { 2 - 3 } & 4 & $10.33 \mathrm{~m}$ \\
\cline { 2 - 3 } & 5 & $13.33 \mathrm{~m}$ \\
\hline
\end{tabular}

Figure 4. Measurement setup for the general embedded track.

\begin{tabular}{|c|c|c|}
\hline & Point & Distance \\
\cline { 2 - 3 } & 1 & $1.0 \mathrm{~m}$ \\
\cline { 2 - 3 } & 2 & $3.0 \mathrm{~m}$ \\
\cline { 2 - 3 } & 3 & $6.0 \mathrm{~m}$ \\
\cline { 2 - 3 } & 4 & $9.0 \mathrm{~m}$ \\
\hline
\end{tabular}

Figure 5. Measurement setup for the grass-embedded track.

The noise measurement was performed using a low-profile surface pressure microphone (130A40, PCB Piezotronics, Inc., USA) and with an adaptable modular measurement system for physical signals (CRONOS PL-2, imc Meßsysteme $\mathrm{GmbH}$, Germany). We referenced the selection of measurement points to the standard for noise control on land transport systems from Environmental Protection Administration [8]. The embedded track noise measurement setup consists of a microphone sensor (130A40) at a distance of 15 meters from the rail center and at a height of 1.2 meters from the ground. The microphone sensor faced the LRT, measuring the background noise and traffic noise when the train passes, as shown in Figure 4 and Figure 5.

\section{Results of Numerical Simulation and Measurement}

\subsection{Analysis and Discussion of Vibration Results}

Figure 6 shows a comparison of the numerical simulation results and measurement results for vibration of the general embedded track. It shows that the finite element model could effectively obtain the natural frequency $(3.126-3.426 \mathrm{~Hz})$ of the embedded rail system. In addition to determining the correctness of the dynamic analysis of the moving load, it can also be used as a reference for dynamic performance design of a rail system in order to avoid the structural damage caused by resonance.

Figure 7 shows a comparison between the displacement time histories of the general embedded track. It shows the simulation and measurement results with three displacement peaks when the train passed over the general embedded track with a speed of around $10-11 \mathrm{~km} / \mathrm{hr}$, inducing a displacement of approximately $0.3 \mathrm{~mm}$.

\subsection{Analysis and Discussion of Noise Results}

The measurement and numerical simulation results for low-frequency noise of 


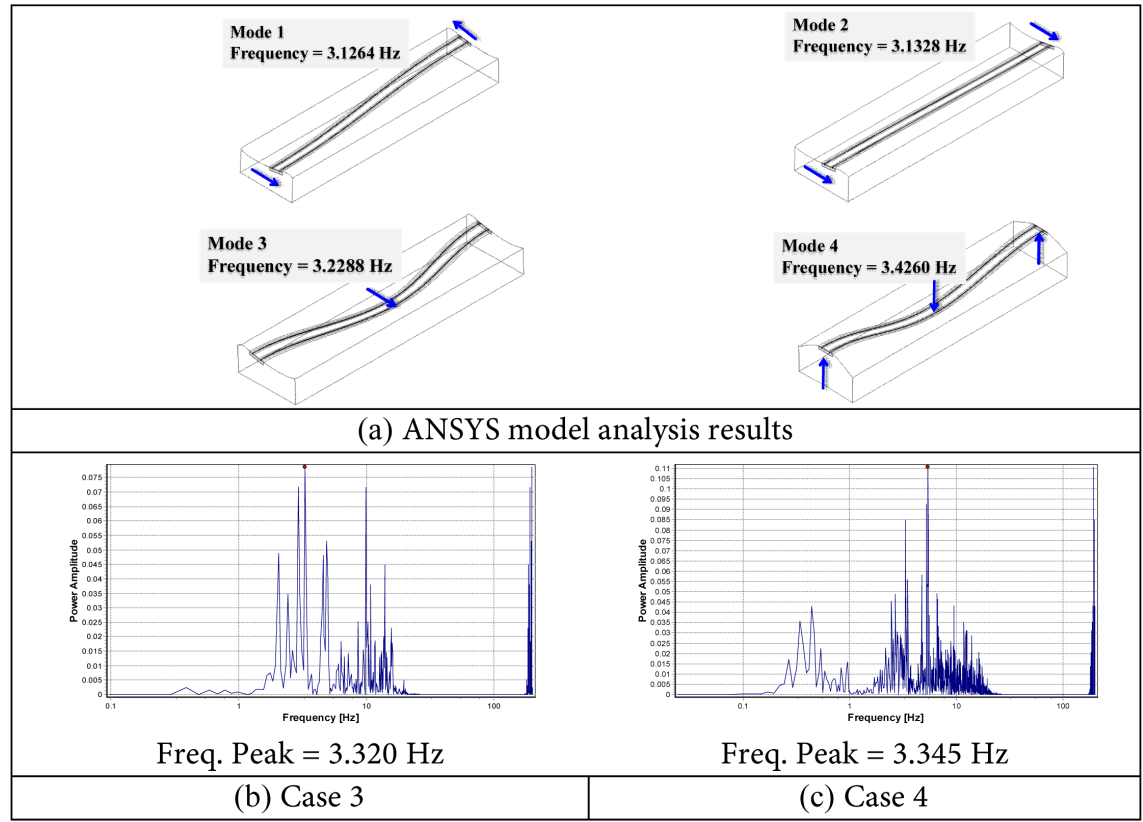

Figure 6. Comparison of vibration results for the general embedded track: (a) numerical results, (b) and (c) measurement results.

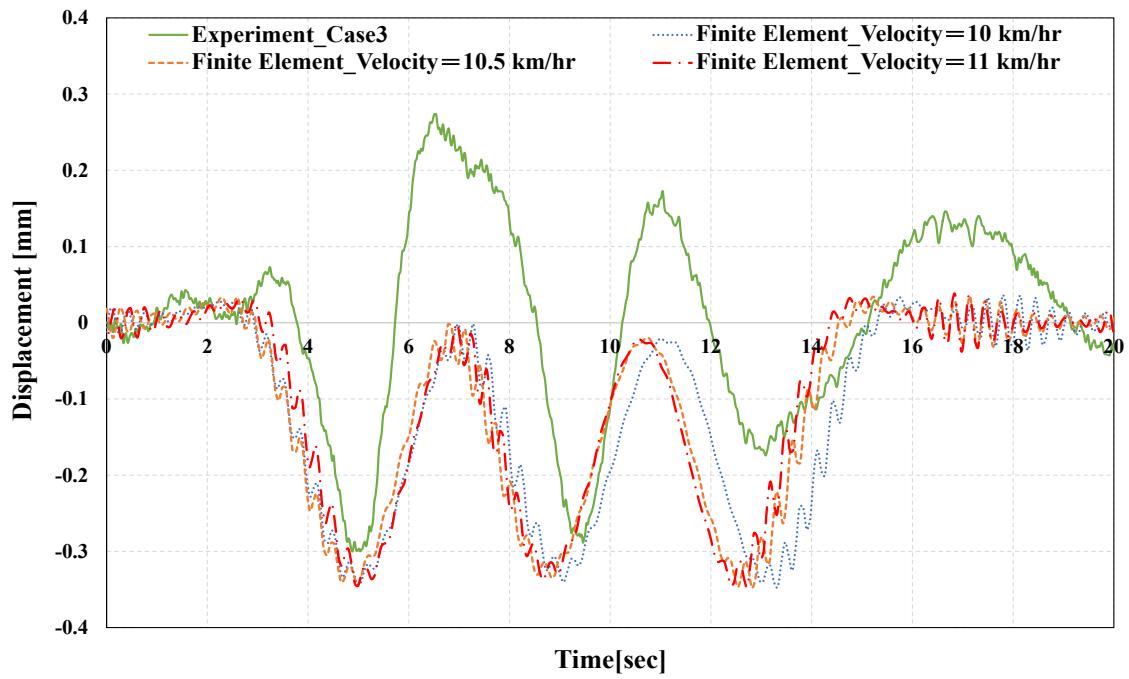

Figure 7. Comparison of displacement time histories for the general embedded track.

the general embedded track are shown in Figure 8. The first three peaks of the noise spectrum simulation results lie at $22.461 \mathrm{~Hz}, 33.569 \mathrm{~Hz}$, and $44.044 \mathrm{~Hz}$ respectively, while the peak of the local noise measurement spectrum lies between 33.2 to $33.5 \mathrm{~Hz}$. This indicates that the LMS Virtual. Lab numerical simulation can effectively simulate low-frequency noise radiation as a train passes for reference in future noise reduction of embedded rail tracks.

\section{Parametric Study on Vibration and Noise}

This section considers the train speed, soil material, and encapsulation material 


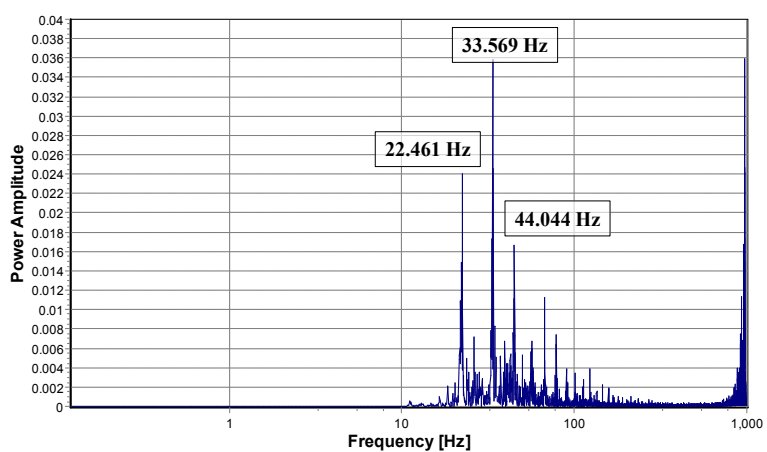

(a)

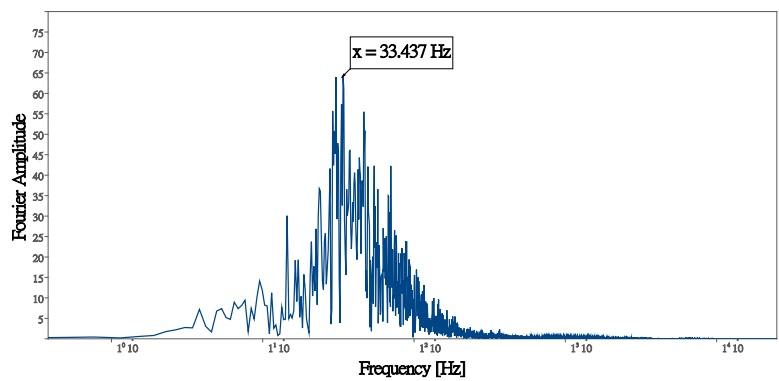

(b)

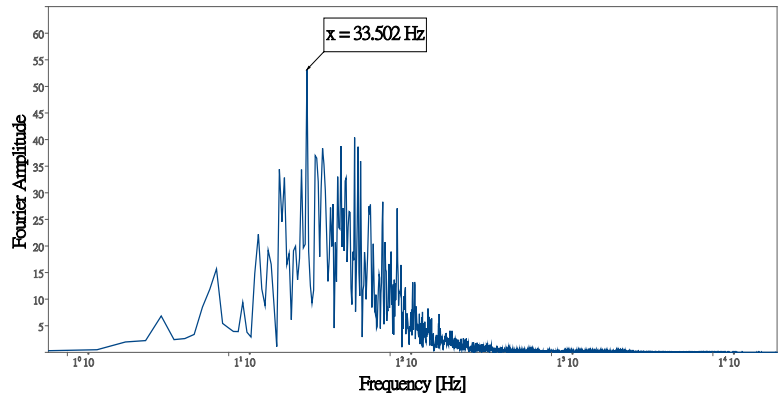

(c)

Figure 8. Comparison of noise results for the general embedded track: (a) numerical results; (b) and (c) measurement results

as the three basic parameters. The finite element model and numerical analysis procedure established in this paper are used in the parametric study in order to understand the sensitivity of each parameter to vibration and noise.

Figure 9 shows the maximum displacement and maximum sound pressure level of the embedded track at different train speeds $(10,25$, and $40 \mathrm{~km} / \mathrm{hr})$. It shows that if the train speed increases, the maximum sound pressure level also increases, but the maximum displacement decreases. Figure 10 shows the maximum displacement and maximum sound pressure level of the embedded track at different soil elastic moduli $(10,25$, and $40 \mathrm{MPa})$. It shows that if the soil elastic modulus increases, the maximum sound pressure level also increases, but the maximum displacement decreases. Figure 11 shows the maximum displacement and maximum sound pressure level of the embedded track at different encapsulation elastic moduli $(0.6,2.6$, and $5 \mathrm{MPa})$. It shows that the maxi- 


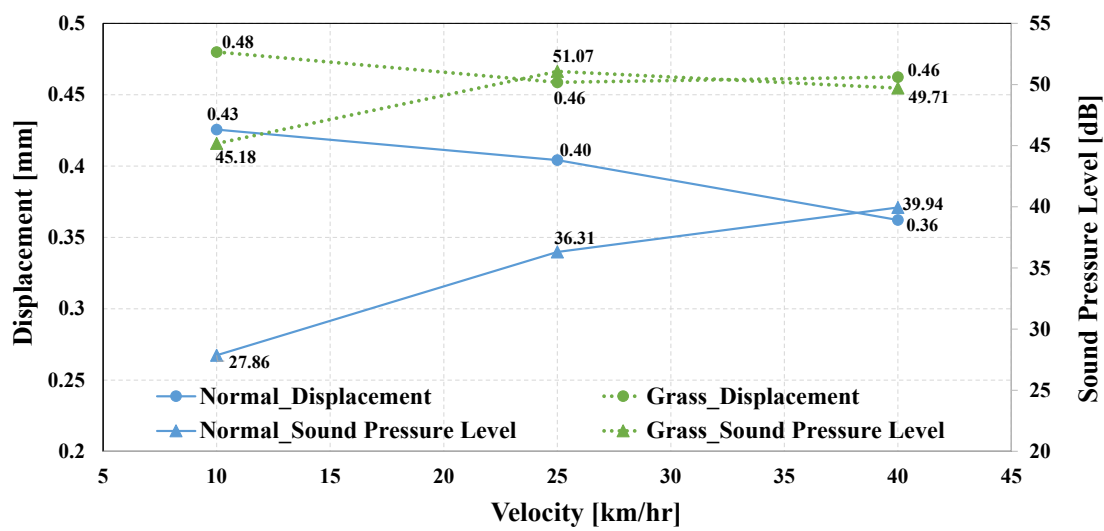

Figure 9. Parametric study on train speed.

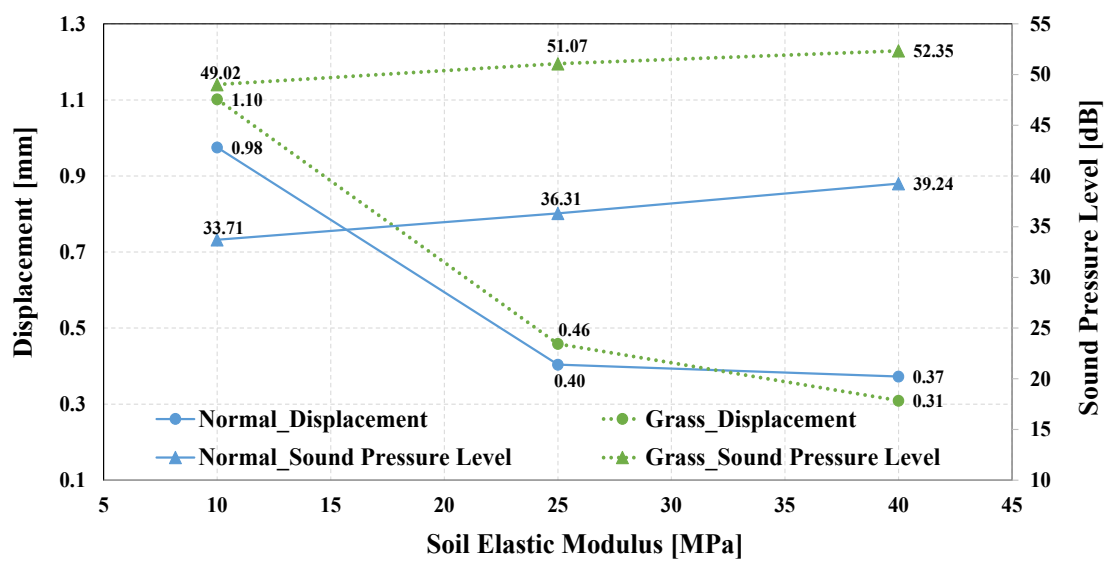

Figure 10. Parametric study on soil elastic modulus.

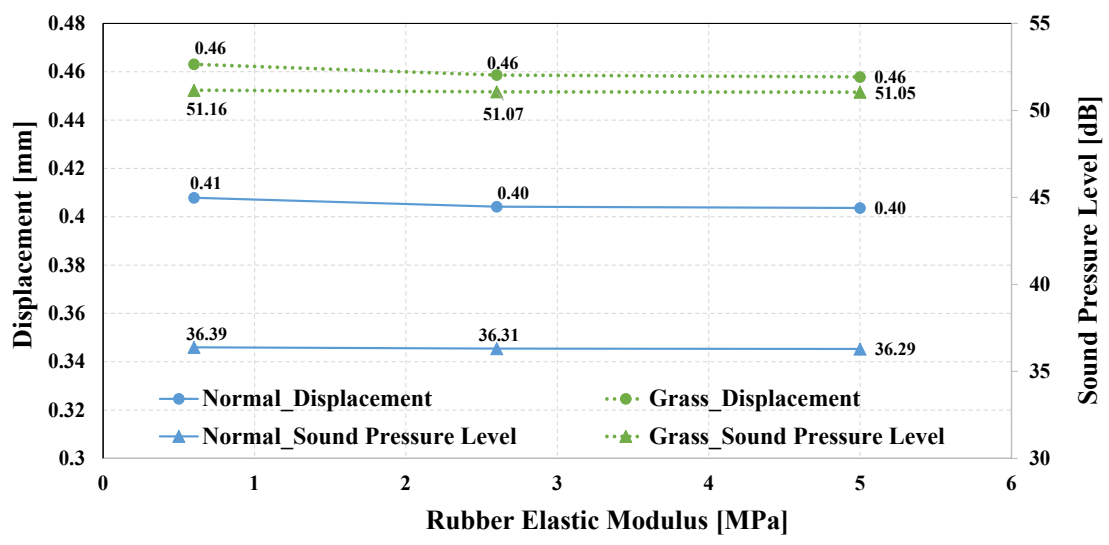

Figure 11. Parametric study on encapsulation elastic modulus.

mum sound pressure level and maximum displacement are not sensitive to the elastic modulus of encapsulation.

\section{Concluding Remarks}

1) The comparison of the simulation and measurement results for the embedded rail system showed that: a) the finite element model could effectively de- 
termine the natural frequency of the embedded rail system and the correctness of the model and b) considering low-frequency noise only, the numerical simulation could effectively reflect the main frequency of low-frequency noise.

2) The parametric study on vibration and noise showed that: a) when the train speed increases, the maximum sound pressure level also increases, but the maximum displacement decreases; b) when the soil elastic modulus increases, the maximum sound pressure level also increases, but the maximum displacement decreases; and c) the maximum sound pressure level and maximum displacement are not sensitive to the elastic modulus of the encapsulation.

3) The vibration and noise frequency response from simulation and measurement results can be applied to dynamic performance design, vibration, and noise reduction for embedded rail systems.

\section{Acknowledgements}

This study was sponsored by CECI Engineering Consultants, Inc., Taiwan under project number CECI 105-05931.

\section{References}

[1] Coenraad, E. (2001) Modern Railway Track. MRT-Productions, The Netherlands, ISBN 90-800324-3-3.

[2] Bernhard, L. (2005) Track Compendium-Formation, Permanent Way, Maintenance, Economics. Eurailpress Tetzlaff-Hestra GmbH \& Co. KG, ISBN 3-7771-0320-9.

[3] Sun, S., Zhang, W.J., Wang, Z.H., Su, W., Wu, C.L. and Bu, Q.H. (2011) Design of Unballasted Track Bridges on Beijing-Tianjin Intercity Railway. Engineering Sciences, 9, 59-70.

[4] Zienkiewicz, O.C. and Taylor, R.L. (1991) The Finite Element Method. McGraw-Hill, UK.

[5] Kirkup, S. (1998) The Boundary Element Method in Acoustics. Integrated Sound Software, UK.

[6] AcrelorMittal (2013) Tram Transport Rail/Carril de tranvía.

[7] Jens Wolffersdorf, S. and Ángel, F. (2013) Construction of Kaohsiung Lrt (Phase 1) Project Final Design. Kaohsiung Mass Rapid Transit, Barcelona.

[8] EPA (2013) Standard for Noise Control on Land Transport Systems. Environmental Protection Administration, Executive Yuan, Taiwan. 
Submit or recommend next manuscript to SCIRP and we will provide best service for you:

Accepting pre-submission inquiries through Email, Facebook, LinkedIn, Twitter, etc. A wide selection of journals (inclusive of 9 subjects, more than 200 journals)

Providing 24-hour high-quality service

User-friendly online submission system

Fair and swift peer-review system

Efficient typesetting and proofreading procedure

Display of the result of downloads and visits, as well as the number of cited articles Maximum dissemination of your research work

Submit your manuscript at: http://papersubmission.scirp.org/

Or contact jamp@scirp.org 